\title{
LA AXIOLOGÍA COMO GUÍA PARA UNA DEFINICIÓN DEL OBJETO DE LA DISCIPLINA CONTABLE EN EL SIGLO XXI
}

\section{AXIOLOGY AS A GUIDELINE FOR A DEFINITION OF THE OBJECT OF THE ACCOUNTING DISCIPLINE IN THE 21ST CENTURY}

\section{SERGI MIGUEL HAUQUE}

Facultad de Ciencias Económicas. Universidad Nacional del Litoral. Facultad de Ciencias Económicas. Universidad Nacional de Entre Ríos. Argentina.

0000-0002-9513-4479

\ sergiohauque@yahoo.com.ar

\section{LEILA DI RUSSC}

Facultad de Ciencias Económicas. Universidad Nacional del Litoral. Facultad de Ciencias Económicas. Universidad Nacional de Entre Ríos. Argentina.

(iD) 0000-0002-8919-3691

$\triangle$ Ihauque@yahoo.com.ar

\section{PALABRAS CLAVE} axiología, contabilidad, responsabilidad social, valores humanos.

\section{KEYWDRDS}

axiology, accounting, social responsibility, human values.

\begin{abstract}
RESUMEN
En el trabajo se señala la importancia de la jerarquía de los valores humanos involucrados en los marcos conceptuales de los sistemas contables para la construcción de informes sociales. Se sostiene aquí que una de las disciplinas que más ha trabajado para la valoración de acciones y hechos reales conforme a patrones de sistemas de valores humanos es la contabilidad. Allí se ha profundizado aún más que en otras disciplinas propiamente axiológicas el estudio y medición de una de las tipologías de los valores humanos: la de los útiles o económicos.

La visión axiológica se basa en la no indiferencia ante las acciones humanas. Es el hombre el que valora y evalúa, sobre la base de una escala de valores, emitiendo juicios en este sentido. El valor económico es uno más dentro de esa complicada jerarquía que permite evaluar acciones. Dado que este valor no encabeza esa escala, los informes sobre la responsabilidad social integral de las organizaciones lo incluyen, pero no le brindan el rol que posee en los tradicionales informes contables privados. Se plantean tres posibles marcos de análisis integrados desde la axiología.

a. La evaluación unidimensional de las acciones de las organizaciones sobre la única base del valor económico para sí misma.

b. Una evaluación en la que también interesa conocer el valor económico que la organización permite crear para el resto de la comunidad actual y futura.

c. Una evaluación más completa teniendo en mira la totalidad de los valores humanos, económicos y no económicos.

El trabajo concluye en que nunca es sencillo proveer información para elegir en estos contextos de hechos inciertos, valores en discusión, altos riesgos y decisiones urgentes, pero debemos hacerlo en función de la compatibilidad entre la jerarquía de valores humanos y las misiones de las organizaciones proveedoras de la información.
\end{abstract}

\begin{abstract}
The present work states the importance of the hierarchy of the human values involved in the conceptual frameworks of accounting systems for the construction of social reports. It is argued here that one of the areas that has worked the most for the valuation of actions and real events according to patterns of human value systems is accounting. The study and assessment of the useful or economic values, which are one of the typologies of human values, have been deeper in this area than in other properly axiological disciplines.

The axiological view is based on non-indifference to human actions. It is men who value and assess, on the basis of a scale of values, making judgements in this regard. The economic value is one more within that complicated hierarchy that makes it possible to assess actions. Since this value does not rank first in said scale, it is included in the reports on corporations' comprehensive social responsibility but not with the role given in traditional private accounting reports.

Three likely frameworks for a comprehensive analysis stemming from the axiology are proposed:

a. The one-dimensional evaluation of the actions of the organisations on the sole basis of economic value for themselves.

b. An evaluation in which it is also worth knowing the economic value that the organisation makes it possible to create for the rest of the present and future communities.

c. A more complete evaluation considering the whole set of human, economic and non-economic values. The work concludes that it is never easy to provide information to choose in contexts of uncertain facts, values under discussion, high risks and urgent decisions, but that we must do so based on the compatibility between the hierarchy of human values and the missions of the organisations that are suppliers of the information.
\end{abstract}

Revista Proyecciones Año 2021 № 15 DOI https://doi.org/10.24215/26185474e014 ISSN 2618-5474

https://revistas.un|p.edu.ar/proyecciones 
"El valor es un hecho enteramente social, un resultado, una categoría social por excelencia. . . Los bienes de valor en su acepción social-teórica no son piezas arrancadas del mundo exterior; su valor significa el sedimento objetivado de las relaciones sociales" (Stolzmann, 1956, pp. 248-249).

El presente trabajo se basa en algunos de los conceptos vertidos en una conferencia brindada por los autores denominada "Revisitando el marco general de los reportes de responsabilidad organizacional", como profesores invitados en la Facultad de Economía y Negocios de la Universidad de Zaragoza (España) el 9 de abril de 2019. Buscamos, en ese momento y también aquí, señalar la importancia de la jerarquía de los valores humanos involucrados en la formulación de los marcos conceptuales generales de los sistemas de información contable para la construcción de informes sociales, que determinan su fundamentación ética. En efecto, si consideramos la ética como la parte de la filosofía que trata del bien y del fundamento de sus valores (Real Academia Española, s.f., definición 5), son estos la única guía posible para determinar un juicio frente a los actos de los seres humanos y de las organizaciones constituidas por esos mismos seres humanos.

A pesar de que pueda sonar paradójico, una de las disciplinas que más ha trabajado y trabaja en el difícil mundo de la valoración de acciones y hechos de la realidad conforme a patrones de sistemas de valores humanos es la contabilidad. En efecto, Ios contadores han desarrollado desde hace siglos esquemas y sistemas de comprobada utilidad para medir los flujos y stocks de los valores económicos, los que resultan, al fin y al cabo, una de las diferentes dimensiones de los valores humanos. Sin darnos cuenta seguramente, hemos profundizado en nuestro campo, quizás aún más que otras disciplinas propiamente axiológicas, en el estudio y medición de una de las tipologías específicas de los valores humanos: la de los útiles o económicos.

Dos autores desde la filosofía nos instan a perseverar en ese camino.

En la doctrina del valor culmina la importancia del concepto de totalidad. También el valor económico es solo un integrante en el sistema más grande de todos los valores que la filosofía nos deja ver como un todo. La filosofía misma no es nada más que un sistema de valores. (Stolzmann, 1956, p. 323)

La teoría pura de los valores útiles constituye el fundamento de la economía, sépanlo o no los economistas. Si los economistas se dan cuenta de ello y estudian axiología antes de empezar propiamente su ciencia económica, y esclarecen sus conceptos del valor útil, entonces veremos cuánto mejor harán la ciencia económica. De modo que en el fondo de toda ciencia económica residen los valores útiles. Fuera pues bueno que ese fundamento estuviese esclarecido por un previo estudio 0 meditación acerca de la teoría pura de los valores útiles. (García Morente, 1957, pp. 382-383)

En efecto, cuando pensamos en los informes de responsabilidad social y ambiental que se han integrado al objeto de la contabilidad desde finales del siglo XX, tenemos en mente instrumentos que nos permiten evaluar el grado de responsabilidad de los entes emisores. Así consideramos a la responsabilidad como el cargo u obligación moral que resulta para alguien del posible yerro en cosa 0 asunto determinado (Real Academia Española, s.f., definición 3), que debe ser evaluado en su grado de cumplimiento. No hay otra forma de evaluar, sino conforme a un sistema de valores humanos, sean económicos o de otra especie, ya que esa acción se define como el acto de estimar, apreciar, calcular el valor de algo (Real Academia Española, s.f., definición 2).

Este proceso requiere la fijación previa de normas, estándares, valores u objetivos contra los cuales comparar ex post las acciones efectivamente realizadas y sus resultados, para que los usuarios de los informes puedan realizar su juicio evaluativo. Sin ese marco previo, resulta difícil comprender cómo preparar informes sistematizadamente para evaluar la responsabilidad social y ambiental de una organización, incluyendo en este concepto sus resultados en el campo de los valores económicos.

\section{LA IMPORTANCIA DE LA DEFINICIÓN DE MARCOS GENERALES PARA LA DISCIPLINA CONTABLE}

Muchas veces la profesión contable, Ilevada por su directo involucramiento con la práctica, desdeña los elementos generales y teóricos que deberían conceptualizar su funcionamiento. Hacer teoría pura sobre marcos generales no resulta demasiado atractivo para la investigación contable, quizás por el temor a que dichos trabajos puedan caracterizarse como metafísicos 0 alejados de un sustento empírico'. Sin embargo, sin previos marcos ni categorías claras, nos enfrentaremos sin herramientas de análisis al caos de los hechos sensibles.

La visión del mainstream contable se acerca al pensamiento del Director de Incubación y Condicionamiento de Un mundo feliz cuando les dice a sus estudiantes, en las primeras páginas de la

' El mainstream positivista es muy importante en la profesión contable. Los que se arriesgan a trabajar en este campo sufren muchas veces lo que señala García Morente (1957) que padecieron quienes en la segunda mitad del siglo XIX se atrevían a cuestionar los trabajos positivistas de Haeckel, Ostwald o Spencer: recibían un "golpe en los nudillos" con la frase "usted es un metafísico". Lo peor sería que ante estas respuestas pensemos "Pobre de mí, soy un metafíisico" y abandonemos este rico campo de investigación (cfr. García Morente, 1957, p. 339). 
genial obra de Aldous Huxley, que son los detalles, y no las ideas generales, las que nos conducen a la felicidad:

—Sólo para darles una idea general —les explicaba. Porque, desde luego, alguna especie de idea general debían tener si habían de llevar a cabo su tarea inteligentemente; pero no demasiado grande si habían de ser buenos y felices miembros de la sociedad, a ser posible. Porque los detalles, como todos sabemos, conducen a la virtud y la felicidad, en tanto que las generalidades son intelectualmente males necesarios. No son los filósofos, sino los que se dedican a la marquetería y los coleccionistas de sellos los que constituyen la columna vertebral de la sociedad. —Mañana —añadió, sonriéndoles con campechanía un tanto amenazadora - empezarán ustedes a trabajar en serio. Y entonces no tendrán tiempo para generalidades. (Huxley, 1932/2020, p. 18)

Respecto de esta temática, a partir de los intentos de integración de los reportes contables tradicionales con los informes de impacto social y ambiental, nos encontramos en la actualidad con un importante conjunto de normas y estándares generales vagos y desarmonizados, que muchas veces se ocupan más de la forma de presentación de los informes que de la profundidad y cohesión de sus contenidos.

Más allá de las normas jurídicas locales o nacionales que obligan 0 proponen la realización de reportes sociales y ambientales para diversos entes, son particularmente destacables los sistemas voluntarios internacionales de estándares para informar especialmente sobre esos aspectos. Esta práctica está especialmente ligada al conjunto de soft law ${ }^{2}$, que se ha multiplicado en las últimas décadas en la búsqueda, casi nunca alcanzada, de normalizar y tornar comparable la información brindada a los stakeholders y a la comunidad en general. Resultan los modelos más utilizados en la actualidad por los entes microeconómicos, con o sin fines de lucro, ya sean públicos 0 privados. Estos estándares muchas veces se complementan con códigos de conducta para el accionar de entes socialmente responsables, de los que no siempre surge claramente la jerarquía de valores que dirige el accionar de cada organización en la búsqueda de la consecución de su misión.

There are two main purposes of corporate responsibility standards. One is to help drive and improve corporate performance through more responsible and accountable business practice. The other is to provide a clear and common understanding of what is meant by such concepts as "sustainable development" and "corporate responsibility (CR)" and the tools that drive them. The importance of such tools to the private sector is clear. Not only has business been a key player in the development of many of the approximately 300 CR tools that exist globally, it is also their leading user, ahead of governments and the nonprofit sector. Such codes, standards and frameworks were developed not as an alternative to government regulations and intergovernmental agreements, but because laws do not - and cannot - provide all the detail that managers require [Hay dos propósitos principales de los estándares de responsabilidad corporativa. Uno es ayudar a impulsar y mejorar el rendimiento corporativo a través de prácticas comerciales más responsables. El otro es proporcionar una comprensión clara y común de lo que se entiende por conceptos tales como "desarrollo sostenible" y "responsabilidad corporativa (RC)" y las herramientas que los impulsan. Su importancia para el sector privado es clara. Las empresas no solo han sido un actor clave en el desarrollo de muchas de las aproximadamente 300 herramientas de RC que existen a nivel mundial, sino que también son sus usuarios principales, por delante de los gobiernos y el sector sin fines de lucro. Dichos códigos, estándares y marcos se desarrollaron no como una alternativa a las regulaciones gubernamentales y los acuerdos intergubernamentales, sino porque las leyes no proporcionan, y no pueden proporcionar todos los detalles que requieren los directores de las empresas]. (Ligteringen y Zadek, 2005, p. 1)

Koerber (2010 como se citó en Marimon et al., 2012) nos confirma lo que seguramente el lector puede intuir ante la existencia de casi 300 sistemas de estándares: a pesar de que cada conjunto de estándares puede tener distintas conformaciones y destinatarios, existe un grado muy importante de solapamiento y falta de armonización entre el contenido de todos estos sistemas normativos.

\section{La conclusión en este contexto es clara:}

It is not surprising that many executives are experiencing 'standards fatigue: a sense of confusion about what tools and standards exist, how they apply, how their costs and benefits stack up, and how Corporate responsibility standards, norms, principles and guidelines aim to provide generally accepted reference points for improving aspects of social and environmental performance. Although mostly voluntary, some are emerging as de facto industry standards that provide the desired legitimacy, consistency and comparability required by business and its stakeholders they relate. Most comprehensive studies of the full universe of CR standards run to hundreds of pages, and often leave the average manager unsure of how to proceed. For their part, many of the CR standards are poorly linked, inconsistently used, and not always transparent about their intended application. [No es sorprendente que muchos ejecutivos estén experimentando 'fatiga de estándares': una sensación de confusión sobre qué herramientas y estándares existen, cómo se aplican, cómo se comparan sus costos y beneficios, y cómo los estándares, normas, principios y pautas de responsabilidad corporativa apuntan a proporcionar puntos de referencia generalmente aceptados para mejorar aspectos del desempeño social y am- 
biental. Aunque en su mayoría son voluntarios, algunos están emergiendo como estándares industriales de facto que brindan la legitimidad, consistencia y comparabilidad deseadas que requieren las empresas y sus partes interesadas con las que se relacionan. La mayoría de los estudios exhaustivos del universo completo de estándares de CR se extienden a cientos de páginas y, a menudo, dejan al administrador promedio inseguro de cómo proceder. Por su parte, muchos de los estándares de CR están mal vinculados, se usan de manera inconsistente y no siempre son transparentes acerca de su aplicación prevista] (Ligteringen y Zadek, 2005, p. 1)

Esta sensación de fatiga y confusión puede también predicarse de las normas generales de la contabilidad tradicional. Resulta realmente difícil de entender que el Conceptual Framework para los IFRS se presente como un marco, pero a la vez permita que cualquier contenido particular de las normas pueda "salirse" de dicho marco y en ese caso prevalezca sobre el enunciado general ${ }^{3}$.

S.P. 1.2. El Marco Conceptual no es una NIIF. Ningún contenido del Marco Conceptual prevalece sobre ninguna Norma o requerimiento de una Norma.

S.P. 1.3. Para cumplir el objetivo de la información financiera con propósito general, el Consejo puede, en ocasiones, especificar requerimientos que se alejen de algunos aspectos del Marco Conceptual. Si el Consejo hace esto, explicará esta falta de observancia en los Fundamentos de las Conclusiones de esa Norma.

S.P. 1.4. El Marco Conceptual puede revisarse periódicamente, a partir de la experiencia que el Consejo haya adquirido trabajando con él. Las revisiones del Marco Conceptual no conducirán automáticamente a cambios en las Normas. Cualquier decisión para modificar una Norma requeriría que el Consejo observara su procedimiento a seguir para añadir un proyecto a su agenda y desarrollar una modificación a esa Norma (International Accounting Standards Board, 2018, p. 5).

En resumen, el marco de nuestro "cuadro normativo" de la contabilidad tradicional permite sin limitaciones que el "pintor" de las normas particulares continúe su "obra" por fuera y aún en contradicción con el "marco" de referencia. ¿Puede considerarse eso realmente un marco?

Poco o casi nada une a la disciplina contable con la física. Existen marcadas diferencias entre una ciencia experimental que busca la unificación de sus teorías sobre la existencia de la materia y la energía, y una disciplina que aún no tiene decidido su estatus epistemológico, pero es factible trazar un paralelo: ¿será posible consensuar un marco coherente para todas las ramas contables, así como la física busca una "teoría del todo"? Y si esto es así: ¿será esto útil o conveniente? Entendemos no solo que el objetivo es razonable, sino también que el proceso de su búsqueda permitirá descubrir nuevas preguntas y nuevas respuestas. Sin embargo, la discusión se mantendrá siempre abierta como en la física o en la química ${ }^{4}$. Es en este camino, que tiene un principio pero creemos que no tiene un fin, que se enmarca el contenido de este trabajo.

\section{LA CONTABILIDAD Y LA AXIOLOGÍA}

\section{¿Cuál podrá ser el hilo unificador de todos los campos de análisis de los informes contables?}

Consideramos que la teoría básica que debe unificar la evaluación de la responsabilidad económica, social y ambiental de las organizaciones, junto con los elementos de la microcontabilidad tradicional y de la macrocontabilidad, es la axiológica, ya que permitiría integrar los valores útiles tradicionales de la economía, con otros valores humanos más significativos. Esta teoría permite analizar la conducta de las organizaciones y de los seres humanos que las integran, a través de un marco común que permita evaluarla dentro del sistema de valores que respete la sociedad en la que se inserta la organización.

La axiología es el sistema formal para identificar y medir los valores. La estructura de valores de las personas determina sus percepciones y decisiones . . . La evaluación supone establecer prioridades. Se escoge algo en lugar de otra cosa. Se piensa en alguna cosa en relación con las demás y se decide cuál es la mejor. (Casares Ripol, 2011, p. 45)

La visión axiológica se basa esencialmente en la no indiferencia ante las cosas y las acciones humanas. Es el hombre el que valora y evalúa, sobre la base de la jerarquía de valores, pudiendo emitir juicios en este sentido. El valor económico es uno más dentro de una complicada jerarquía que permite evaluar y juzgar acciones. Precisamente los valores económicos no son los prevalentes en la escala, y es así que cualquier informe sobre la responsabilidad integral de las organizaciones los incluye, pero no les brinda el mismo rol que poseen en los informes de rendición de cuentas privadas de esas mismas organizaciones.

Del conjunto de objetos identificables en la ontología, los valores son los que llevan impregnados en su esencia la visión del hombre en sociedad. Creemos que se ha profundizado muy poco en este campo y hay aún mucho por trabajar.

\footnotetext{
${ }^{3}$ Similar situación se vive con el contenido de la Resolución Técnica Nro. 16 considerada como el "marco conceptual argentino".

${ }^{4}$ Es importante entender que no es necesario conocer la respuesta a todas las preguntas para imaginarnos el resultado final. Recordemos que cuando Mendeléyev buscaba una "Tabla Periódica de Elementos", esta fue formulada con "casilleros vacíos" sin que siquiera hubieran sido descubiertos la totalidad de los elementos que hoy la conforman. Cfr. Hauque y Di Russo (2013).

${ }^{5}$ En este tema sequimos las líneas generales planteadas en el esquema de desarrollo de Hauque et al. (2016).
} 
The lack of a clinically relevant methodology for the study of values in the field of psychology didn't stop professor Milton Rokeach from proclaiming that the concept of value is at once the most important, least studied, and least understood concept in all of psychology and the social sciences [cursivas añadidas] [La falta de una metodología clínicamente relevante para el estudio de los valores en el campo de la psicología no detuvieron al profesor Milton Rokeach de anunciar que e/ concepto de valor es a la vez el más importante, el menos estudiado y el concepto menos comprendido de toda la psicología y de las ciencias sociales [cursivas añadidas]]. (Pomeroy, 2013, p. 94)

La axiología, aún no demasiado desarrollada y con todas sus limitaciones, puede darnos un marco más amplio y adecuado para explicitar el cumplimiento de responsabilidades sociales en diversos aspectos, incluyendo en ellas las económicas. Un prerrequisito para este paso es aceptar la existencia de algún tipo de ancla en la objetividad de los valores. Si pensamos, como los seguidores de Protágoras, que "el hombre es la medida de todas las cosas" (como se citó en García, 2005, p. 1), caemos en un escepticismo relativista que nos impedirá evaluar intersubjetivamente las acciones organizacionales.

Es cierto que los valores no tienen una única estructura y son opinables, pero puede argumentarse sobre ellos e intentar educar y convencer en relación con los mismos. Actualmente, los valores económicos tienen procedimientos de evaluación bastante objetivos y generalizados, como nos muestran los desarrollos contables difundidos. ¿Por qué no pensar en desarrollar esa capacidad de evaluación para las distintas acciones a la luz de los restantes valores humanos? No tendrán que ser precisas y obligatoriamente evaluaciones cuantitativas, pero sí deberán brindarnos un orden más claro respecto de qué acciones pueden ser evaluadas positivamente y cuáles no, sobre la base de la polaridad de los valores.

Si pensamos que los valores son subjetivos, no podremos intentar convencer a nadie de que nuestra visión subjetiva es mejor que la de otra persona particular. Valorar cualquier acción o conducta será un simple ensayo personal, distante de un informe que resulte intersubjetivamente contrastable. No será posible buscar estándares de consenso para informes al respecto. A favor de la postura objetiva, se puede mostrar lo avanzado de las aproximaciones de medición de la ciencia económica y la disciplina contable en el análisis de los valores del agrado 0 utilidad.

De los valores se puede discutir, y si se puede discutir de los valores es que a la base de la discusión está la convicción profunda de que son objetivos, de que están ahí, de que no son simplemente el peso o residuo del agrado o desagrado. (García Morente, 1957, p. 373)

A pesar de que los axiólogos sostienen que el mundo de los valores es "extraño a la cantidad" (Casares Ripol, 2011, p. 47), entendemos que esta idea no es extrapolable a todos sus ámbitos, ya que en el campo de los valores de la utilidad o económicos es posible teorizar cuantitativamente, siempre teniendo en mira las limitaciones que implican (cfr. entre otros Di Fenizio, 1958).

Los hombres pueden intuir tales valores o no intuirlos; ser ciegos o clarividentes para ellos; pero el hecho que haya una relatividad histórica en el hombre y en sus actos de percepción e intuición de valores, no nos autoriza en modo alguno a trasladar esa relatividad histórica del hombre a los valores, y decir que porque el hombre es el relativo . . . Io sean también los valores. (García Morente, 1957, p.378)

Los valores humanos mantienen una dada jerarquía entre ellos. "Desde el punto de vista de su ordenación jerárquica, Scheler distingue cuatro grupos de modalidades en los valores; a) valores de lo agradable y lo desagradable; b) valores vitales; c) valores espirituales; y, d) valores religiosos" (Rumoroso Rodríguez, 2013, pp. 39-40). No tenemos dudas de que los valores vitales, espirituales y religiosos son superiores a los económicos. Sin embargo, siempre será necesario obtener satisfacción para los niveles inferiores de valoración, previo a poder realizar evaluaciones respecto de la realización de valores más elevados. Quien no tiene satisfechas las necesidades primarias no es lo suficientemente libre en sus acciones para ser evaluado, por ejemplo, en relación a la verdad, porque quizás mentirá obligado para obtener su sustento. Quien no se encuentra sano no podrá ser evaluado cabalmente, por ejemplo, en cuanto a su respeto del valor justicia, ya que quizás aceptará una norma injusta para verse libre de la enfermedad. El mundo de la necesidad no se condice con la libertad que requiere la acción humana para poder ser valorada correctamente. "Este análisis conduce a la conclusión de que lo único que puede ser verdaderamente bueno o malo es la voluntad humana" (García Morente, 1957, p. 311).

Esa voluntad humana de los integrantes de las organizaciones debe ser lo suficientemente libre para permitir la evaluación del conjunto de las acciones de ese ente. Habrá que tener en cuenta que la libertad de los integrantes de una organización es una condición necesaria, pero no suficiente para evaluar la responsabilidad social de una organización.

Una forma para intentar descubrir la jerarquía de valores para una sociedad es analizar su Código Penal y su ordenamiento sobre la base de los bienes jurídicos protegidos ante cada grupo de delitos tipificados. Así, los delitos contra las personas y contra la libertad son considerados normalmente más graves que los delitos contra la propiedad por la cuantía de la pena que tienen asignada, como consecuencia implícita de que los valores de la vida, la salud y la libertad de las personas son superiores a los económicos de la utilidad (Cfr. Casares Ripol, 2011, pp. 48-49 y García Morente, 1957, Lección XXIV).

En resumen, consideramos que la axiología debe resultar el eje articulador del marco para la evaluación de la responsabilidad integral de las organizaciones y de los seres humanos que las com- 
ponen. A continuación, mostraremos algunas posibilidades para la definición previa de esos marcos, en consonancia con distintas posibles posiciones axiológicas.

\section{POSIBLES MARCOS EN FUNCIÓN DE LOS VALORES INVOLUCRADOS EN EL DESARROLLO DE LA MISIÓN DE LAS ORGANIZACIONES}

\section{Consideraciones Preliminares}

Intentaremos a continuación plantear diferentes marcos posibles para la evaluación de las acciones de las organizaciones, sobre la base de los valores a tener en cuenta en el desarrollo de sus misiones.

Le pediremos al lector que, al mismo tiempo de avanzar en los distintos marcos propuestos, intente hacer un ensayo de pensar cómo podría asimilarse una "rendición de cuentas social" de las acciones de una organización con la que él mismo podría realizar sobre sus propias acciones personales. Los invitamos a suponer que periódicamente también nosotros deberíamos presentar una "rendición de cuentas social", en la que informemos a la sociedad, a la luz de los valores que declaramos aceptar y de la misión que podamos haber fijado para nuestras vidas, sobre los resultados de nuestras acciones. Resulta difícil ubicarse uno mismo como objeto de estudio, pero este esfuerzo nos permite acercarnos directamente al problema y plantearnos un conjunto inicial de preguntas que deberemos responder coherentemente en función del marco que aceptemos como referencia.

- ¿Tenemos clara previamente la misión de nuestras vidas? ¿Y el marco de valores que pretendemos respetar en una determinada jerarquía?

Si efectivamente lo conocemos, ¿quién lo definió? ¿Nosotros libremente 0 fue impuesto o sugerido desde nuestro exterior? ¿Nuestros stakeholders están identificados y lo conocen claramente? ¿Tenemos "agendas ocultas" que sólo hablamos con nuestro psicólogo de confianza?

- ¿Qué incluiríamos y que no en un informe sobre la base del estándar Integrated Report ${ }^{6}$ de un año de nuestras vidas?

- ¿A quiénes consideramos capacitados para realizar una revisión de auditoría del contenido de ese informe?
La Evaluación Unidimensional de las Acciones de las Organizaciones sobre la Base del Valor Económico de su Propiedad

There is one and only one social responsibility of business - to use its resources and engage in activities designed to increase its profits so long as it stays within the rules of the game, which is to say, engages in open and free competition without deception or fraud [Existe una y solo una responsabilidad social de las empresas: utilizar sus recursos y participar en actividades diseñadas para aumentar sus ganancias siempre que se mantenga dentro de las reglas del juego, es decir, se involucre en una competencia abierta y libre, sin engaños ni fraude]. (Friedman, 1970, párr. 33)

Esta conocida frase de Friedman resulta bastante chocante desde el punto de vista social, pero tiene la gran ventaja de resultar mucho más clara al momento de definir la misión y valores que deben guiar a la organización empresa. En efecto, el lucro es la única misión y a la vez la única función social de la empresa. Maximizar la creación de valor económico absoluto como aumento de la propiedad privada de la propia organización resulta la forma en que se realiza dicha misión. La responsabilidad social ante los stakeholders coincide con la rendición de cuentas ante los shareholders, gracias a la "mano invisible" de Smith, resignificada por los economistas neoclásicos ${ }^{7}$. La contabilidad patrimonial es la respuesta más adecuada a este modelo de misión y valores de la organización. Sus informes contables tradicionales nos informarán sobre el resultado económico propio obtenido, y de esa forma nos permitirán evaluar la responsabilidad en el accionar de la empresa frente a sus accionistas y a la vez ante la sociedad.

Surgirán seguramente algunos problemas al momento de definir más precisamente cuándo y ante qué situaciones concretas se crea, destruye o modifica el valor económico para la empresa ${ }^{8}$, pero existe ya mucha doctrina y normativa sobre el tema desde que se crearon los sistemas de información contable.

El problema del valor económico aparece así "resuelto" al asimilarlo al "precio en el mercado". En este contexto positivista neoclásico económico, toda discusión sobre objetos de difícil identificación empírica fue desterrada por resultar "metafísica", especialmente las discusiones ricardianas y marxistas sobre cuál era el "nóumeno" del valor económico. La consecuencia es que el concepto de valor se reduce al precio en el mercado de los bienes y

${ }^{6}$ Dada la existencia de la antes citada "fatiga de estándares", a los efectos de este trabaio, cuando utilicemos un ejemplo de estándares establecidos, utilizaremos el caso del Integrated Report, sin que esto implique una un ejemplo de estándares establecidos, utilizaremos el caso del Integrated Report, sin que esto implique una opinión sobre su importancia dentro de los más de 300 conocidos.

${ }^{7}$ De más está decir que esta postura tiene ya muy pocos defensores, aun dentro del paradigma del mainstream económico tradicional. Cfr. entre otros Lipsey y Lancaster (1957).

${ }^{8}$ Prevalece desde el inicio del siglo XXI en la totalidad de los marcos conceptuales micro y macrocontables la utilización de la regla del devengado. Cfr. entre otros Naciones Unidas et al. (2008), "Las transacciones ... se registran en el momento en que se crea, transforma o extingue el valor económico" (Punto 2.55). 
servicios concretos. Así las cosas, para el sistema neoclásico, "the agreed price of a good is also its value" [el precio acordado de un bien es también su valor] (Koslowsky, 1996, p. 16). Toda discusión sobre la existencia de determinantes del valor económico externos a la oferta y demanda de los mercados concretos desaparece de plano. En esta visión, el concepto de valor diferenciado del precio no tiene razón de ser y el reduccionismo económico empirista absorbe cualquier discusión sobre el resto de los valores humanos en las organizaciones. El lector podrá observar en el sistema de la contabilidad tradicional que son solo precios de distintos mercados, los que se utilizan para valorar los flujos y los stocks que se muestran en esos informes contables.

Es así que "no extraña que uno se canse en asistir a las controversias sobre el valor y se contente con una mera descripción de los fenómenos particulares ligados con el precio, sin tratar de estudiar a fondo el oculto enigma del valor" (Stolzmann, 1956, p. 323-324).

Esos flujos de valor económico que se tratan de maximizar se cristalizan y acumulan en los stocks de capital propio ${ }^{9}$, que se busca incrementar como resultado de la maximización del valor creado para la propia empresa.

Revisitando la historia de las teorías económicas, especialmente de la primera mitad del siglo XX, es importante recordar los desarrollos sobre el sistema de fallas de mercado que refutan la posibilidad de asimilar el bienestar general a la suma algebraica de las funciones de bienestar individuales. Las imperfecciones en los mercados, la existencia de bienes públicos y preferentes, las externalidades, la información asimétrica y otros descubrimientos del siglo XX nos permiten hoy asegurar que esa asimilación dista mucho de ser cierta.

Teniendo en cuenta que la dirección de la organización no es omnisciente y que se desarrolla en un contexto de "racionalidad limitada", el objetivo maximizador resulta imposible de cumplir, planteándose en la realidad metas más modestas ligadas a niveles de rentabilidad sobre el capital invertido. Hay que tener en cuenta que la organización como conjunto no puede asimilarse a una "función de producción" única e indivisible, con una única función de beneficio objetivo a maximizar. Sus integrantes son seres humanos concretos que toman decisiones específicas, teniendo también en mira la maximización de sus propias funciones de satisfacción.

Esta visión también pone en discusión el significado concreto de "without deception or fraud" de la máxima friedmaniana. El objetivo maximizador incondicional se cumple cuando se obtienen beneficios aun con acciones borderline ${ }^{10}$ respecto de las regulaciones vigentes, siempre y cuando un bajo de nivel de enforcement efectivo de la norma haga percibir una baja probabilidad de que el regulador llegue a conocer o cuestionar efectivamente ese accionar.

La aparente solución surgida de asimilar totalmente el fenómeno "tangible" del precio al "oculto enigma" del valor económi-
$C 0^{11}$ también se pone en crisis al observar la existencia de bienes y servicios que no poseen precio en los mercados (bienes públicos y preferentes, recursos de propiedad común, servicios de voluntariado, etc. $)^{12}$.

Si, como planteamos al inicio de esta sección, intentamos asimilar el caso de las "rendiciones sociales de cuentas" a nuestra situación personal, podemos intentar imaginar un caso que se rija por la misión y los valores que define la frase de Friedman (1970) que encabeza este punto. Una persona que se defina en este modelo pensará exclusivamente en maximizar su propia utilidad, justificando su accionar en la seguridad de que su comportamiento maximiza el bienestar de toda la comunidad. Es así que este modelo de ser humano se acercaría a la concepción estereotipada del homo economicus neoclásico. Su única misión sería maximizar el valor económico absoluto de su propiedad privada, dentro de la ley, 0 "jugando" con las probabilidades de su proceso de enforcement efectivo. Será evidentemente una persona que no deja propinas voluntarias en los lugares a los que no planea volver, más allá de que la atención recibida haya sido excelente. Desconoce la posibilidad de ser empático con otras personas.

Es tan así que ha llegado a ser caracterizado como un modelo de un verdadero "psicópata", a pesar de que muchas veces resulta un "ejemplo" a seguir por muchas sociedades ${ }^{13}$.

Será interesante conjeturar sobre cuál sería el posible contenido del informe de responsabilidad social de un homo --modélico. Seguramente mostrará exclusivamente los resultados económicos que obtuvo durante el período en cuestión, señalando los cambios en el valor de patrimonio y sus posibilidades de consumo propio que le brindó la creación de valor económico del período. Además, si considera que explicitar su verdadera misión y su verdadera jerarquía de valores en el informe a presentar puede afectar negativamente sus perspectivas de obtener futuros resultados económicos positivos en transacciones con personas "altruistas", seguramente no los incluirá explícitamente en su reporte. Igualmente sucederá con toda información que le convenga ocultar, siempre que pueda superar un proceso razonable de auditoría, para el hipotético caso de que el informe sea sometido a una revisión por terceros independientes.

2Dado que a nivel agregado los pasivos de un ente son activos recíprocos de otros y deberían cancelarse en el caso de una consolidación, es razonable la postura de algunos autores que señalan que han llamado capital "a aquella suma de los valores de cambio que sirve de base real a una empresa capitalista. La palabra equivale por lo tanto, a lo que la teneduría de libros por partida doble llama activo del negocio" (Sombart, 1984, p. 143). ${ }^{10}$ Como la elusión fiscal y la planificación fiscal agresiva. Cfr. entre otros Sikka (2010).

"Y Y en una concepción axiológica extremadamente reduccionista, aun a valor lato sensu.

${ }^{12}$ Recordemos que la eterna discusión sobre las diferencias entre precio, valor económico y el resto de los valores humanos es señalada desde antaño por la literatura. "What is a cynic? ... A man who knows the price of everything and the value of nothing. [i. Que es un cínico? ... Un hombre que conoce el precio de todo y e

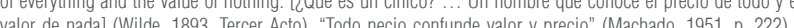
(192. 222) "solo el necio confunde valor con precio" "Qucevedo, 1611, como se cito en Esteban y Sanchez, 2003, parr. 1). No es casualidad que la diferencia entre valor y precio sea resaltada por escritores anteriores al neoclasicismo económico o que sostienen la superioridad de los valores estéticos por encima de los económicos.

13 "We see a person who is intelligent, driven to excel and to dominate other people, and capable of impulse control and of working toward long-term goals. In other words, Homo economicus is the prototypical member of the social and economic elite." [Vemos a una persona que es inteligente, impulsada a sobresalir y dominar a otras personas, y capaz de controlar los impulsos y trabajar hacia metas a largo plazo. En otras palabras, e Homo economicus es el miembro prototíico de la élite social y económical (Yamagishi et al., 2014, p.12). 
El valor "verdad" debería ceder evidentemente ante los valores económicos creados para sí mismo. Es posible asimilar, mutatis mutandis, este modelo al del informe de una organización que asuma similar misión y valores al concepto de Friedman. Habrá que considerar que en las sociedades del siglo XXI estas organizaciones "psicopáticas" resultan, en la generalidad de los casos, mal vistas por las comunidades en las que se insertan.

\section{Crisis de la Evaluación de los Sistemas Tradicionales. ¿Y si la Empatía Social También Determina que Interesa Conocer el Valor Económico que la Organización Permite Crear para Otras Organizaciones y Seres Humanos Dis- tintos a los Shareholders?}

En las sociedades modernas, entendemos que la empatía resulta un elemento importante a tener en cuenta al realizar la evaluación social de las acciones de los seres humanos y de las organizaciones que ellos forman. Así las cosas, sin que esto implique perder de vista la necesidad de buscar el lucro propio, una empresa moderna necesita considerar e informar sobre los efectos que producen sus acciones sobre los flujos y stocks de valor económico de propiedad de terceros.

El valor económico, cuyos flujos se cristalizan en el stock capital, posee en las sociedades que reconocen el derecho a la propiedad privada la especial facultad de ligarse directamente mediante lazos jurídicos a sus propietarios. Recordemos que a pesar de ello

en el estado social, en cualquier estado excepto el de absoluto aislamiento, no se puede disponer de nada sin el consentimiento de la sociedad 0 , más bien de aquellos que disponen de su fuerza activa. Incluso lo que una persona ha producido con su propio trabajo, sin ayuda de nadie, no puede retenerlo si no es con el permiso de la sociedad. Esta no solo puede quitárselo, sino que los individuos podrían y querrían quitárselo solo con que la sociedad permaneciera pasiva, si no interviniera en masse, 0 empleara y pagara a personas con el fin de impedir que le molesten en su posesión. (Mill, 1848/1978, pp. 191-192)

En este contexto de reconocimiento de la existencia de la propiedad privada, es dable separar entre los efectos que producen las acciones de las organizaciones respecto del valor económico propio y ajeno. Es así que las misiones de las organizaciones modernas refieren también al valor económico creado-- para otros, para los stakeholders y no solo para el propio ente y sus shareholders. Se empieza así a hablar y aceptar el concepto de "valor compartido", sin quizás entender muy bien a qué nos referimos. Resulta aquí muy atinado empezar a aplicar la máxima "there's no sense in being precise when you don't even know what you're talking about" [No tiene sentido ser preciso cuando ni siquiera sabemos de lo que estamos hablando] (Von Neuman, s.f., como se citó en Mersch, 2019, párr. 1).
La noción de valor económico "compartido" genera problemas de interpretación en el mundo de los bienes y servicios privados sujetos evidentemente a los principios de exclusión y rivalidad, solo inaplicables a los bienes públicos ${ }^{15}$. Es obvio que un mismo bien o servicio privado no puede ser gozado en plenitud por dos sujetos, por lo que nos encontraremos ante dos magnitudes a evaluar: la cantidad de valor económico flujo y de capital stock generados ${ }^{16}$ para el propio ente y los mismos conceptos generados para otros integrantes de la comunidad, contando entre ellos no solo al Estado y las organizaciones direccionadas al bien común, sino también al resto de las organizaciones con fines de lucro y de los seres humanos que constituyen esa comunidad, en la actualidad y en el futuro. Aparece aquí la necesidad de que los informes contables evalúen los Ilamados efectos externos o externalidades positivas y negativas que generan las acciones de las organizaciones emisoras de los reportes.

Más allá de lo censurable de la misión y los valores del homo economicus, la evaluación de sus acciones era mucho más sencilla. Existía una única misión y un único valor a maximizar. Quizás sea poco humano, pero su evaluación es relativamente mucho más fácil de resolver, respecto de los problemas que empezamos a observar en estos nuevos contextos. Todo resulta más complejo, porque empezamos a tener varios objetivos para evaluar y definir en consecuencia las responsabilidades sociales de la organización. Cuando pensemos en nuestro ensayo de reporte social individual, deberemos incluir no solo las vicisitudes del valor económico de nuestra propiedad exclusiva, sino también los efectos que nuestras acciones generaron sobre los flujos y los stocks de valor económico de la sociedad actual y de las generaciones futuras.

Al mismo tiempo seguimos enfrentando, y con mayor complejidad, el viejo problema de qué es en realidad "valor"17 y por ende qué es "capital". Son palabras que utilizamos a diario en nuestra labor pero no muchas veces nos detenemos a reflexionar sobre su verdadero alcance. Creemos importante "the great care that needs to be taken in examining sometimes taken-for-granted words in common use in the field" [el gran cuidado que debemos tener al examinar algunas veces palabras de uso común en el campo de estudio cuyo contenido se da por sentado] (Jorgensen, 2005, p.24).
${ }^{14}$ No solo se debería informar sobre la "creación" de valor económico, sino también sobre sus modificaciones cualicuantitativas y su posible destrucción.

${ }^{15}$ Los mecanismos óptimos de producción y provisión de los bienes públicos resultan un importante capítulo de los contenidos de la Economía del Sector Público. Cfr. entre otros Stiglitz y Rosengard (2016).

${ }^{16}$ Recordemos nuevamente que resulta más correcto hablar de "vicisitudes" del valor económico y no solo de creación. Debemos incluir los casos de conservación, disminución y aún de su destrucción (piénsese por ejemplo en los efectos sobre el valor económico de terceros que produce cualquier organización que se denomine ejército). La versión 2021 del Integrated Reporting Framework resalta este aspecto cuando señala "The primary purpose of an integrated report is to explain to providers of financial capital how an organization creates, preserves or erodes value over time" [El objetivo principal del reporte integrado es explicar a los proveedores del capital financiero como una organización crea, preserva o erosiona el valor a través del tiempo] [cursivas añadidas] (Value Reporting Foundation, 2021, p.6).

${ }^{17}$ Sin tener ahora siquiera el recurso de asimilarlo totalmente al fenómeno del precio en el mercado. 
En este marco que aquí proponemos, al menos nos constreñimos al análisis del "valor económico" propio y de terceros, intentando no "mezclarlo" con el resto de los valores humanos. Sin embargo, hay que tener en cuenta que esto no resulta claro en los marcos conceptuales más difundidos sobre reportes sociales que no definen claramente la cuestión. Por ejemplo, el Integrated Reporting (IR) Framework menciona 131 veces el concepto valor ${ }^{18}$ y 157 veces capital (Value Reporting Foundation $\left.{ }^{19}, 2021\right)$. Describe un conjunto de etapas del proceso de creación, preservación y/0 erosión del valor. Define capital como "stocks de valor", pero no incluye ninguna definición concreta de valor en su glosario ${ }^{20}$. Se habla de "el valor" y "los capitales", avanzando en una concepción que considera que no existe una sola forma de capital, pero no aclara si son inventarios de valores distintos los que se acumulan en cada uno de los capitales identificados ${ }^{21}$.

En ese mismo marco, se diferencia el valor para el propio ente y el valor para los otros integrantes de la comunidad sosteniendo dogmáticamente que "the ability of an organization to create value for itself is linked to the value it creates for others" [la capacidad de una organización para crear valor para sí misma, está relacionada con el valor que genera para los demás] (Value Reporting Foundation, 2021, p. 17). Se sostiene así una correlación positiva entre estas dos dimensiones, hecho que no siempre puede ser verificado empíricamente. La valoración social de un ente tiene también que ver con los efectos que producen sus acciones sobre el "valor económico" propiedad de su comunidad y sus stakeholders, pero resulta difícil saber si esta misión está valorada en todos los casos con una mayor o una menor ponderación que el lucro propio.

En un intento de rescate de la partida doble, interactuando entre la macrocontabilidad y microcontabilidad, surge el Estado de Valor Agregado como intento de respuesta contable aún muy tradicional ante este nuevo desafío. Sin embargo, los sistemas de información contable no captan todos los efectos que las acciones de las organizaciones producen sobre el valor económico y los capitales "ajenos", por lo que resulta necesario reformular esos sistemas para pensar integralmente el problema, especialmente para captar el fenómeno económico de las externalidades positivas y negativas (cfr. entre otros Mook, 2007). Aparece entonces la dificultad para medir el valor económico "difuso" que generan las externalidades,

\footnotetext{
${ }^{18}$ En ningún caso acompañado del adjetivo económico.

${ }^{19}$ Conformada a partir de Junio de 2021 sobre la base de la fusión del International Integrated Reporting Council (IIRC) y el Sustainability Accounting Standards Board (SASB), este último surgido originalmente de la International Financial Reporting Standard (IFRS) Foundation demostrando un paso más de la integración entre las distintas ramas contables sobre la base del vocablo valor

Se mantiene en las versiones 2013 y 2021 del IIRR Framework una "circularidad" entre la definición de los capitales como stocks de valores y del proceso de creación, preservación y/o erosión del valor como el determnante de los aumentos y disminuciones de los capitales. El concento de valor no muestra un contenido concreto y

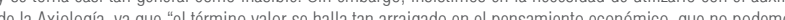
prescindir de él" (Mattessich, 2002, p. 161)

El Marco establece seis categorías de capitales: financiero, industrial, intelectual, humano, social y relacional, y natural. Casi como una confesión explíita de que esa es solo una de las tantas propuestas posibles, el marco aclara que las organizaciones que preparen un informe integrado no están obligadas a adoptar esta categorización o estructurar su informe conforme a estos capitales. Si hay un valor y varios capitales, ¿existiría así un solo
} valor que permite conformar el stock de varios distintos capitales? por la lejanía que poseen respecto de los "precios en los mercados", precisamente por no estar internalizadas.

A pesar de estas dificultades señaladas, dentro de este marco será necesario determinar, lo más acertadamente posible, los efectos económicos directos e indirectos de las acciones de la organización emisora del reporte sobre la comunidad en su totalidad y sobre sus individuos y grupos específicos en particular, incluyendo también estos efectos que probablemente se derramen sobre las generaciones futuras. La información no podrá limitarse a los efectos positivos sobre los flujos y stocks de valor económico ajenos, sino que deberá balancearse mostrando a la vez los efectos negativos que esas acciones pudieran haber producido.

Volvamos con este nuevo enfoque al caso de nuestra "rendición de cuentas social” personal. Nuestra misión se complejizó. Ahora debemos crear valor económico y buscar que se cristalice en capital no solo para nosotros, sino también para los demás. Hemos abandonado la postura "psicopática" y nos acercamos a una visión un poco más "empática".

Ahora bien, ¿cómo ponderarán nuestras acciones en favor de la creación de valor económico para los otros? ¿Serán más o menos importantes en la evaluación respecto de las acciones que creen valor para nuestros shareholders? ¿Será mejor para la evaluación que la creación de valor se produzca para terceros habitantes de nuestra ciudad, connacionales o extranjeros? ¿0 quizás llevados por un sentimiento xenófobo nuestra comunidad valore especialmente la destrucción de valor de extranjeros enemigos? ¿Para personas pobres o ricas? ¿Para las generaciones actuales o para las futuras, preservando para ellos el medio ambiente? Aparece aquí el mismo problema que tienen las autoridades económicas de un país cuando tienen que realizar evaluaciones multiobjetivo de los resultados esperados de las políticas económicas que planean implementar.

La única forma de acercarnos a una definición de los parámetros de esta evaluación multiobjetivo será clarificar y transparentar hacia la comunidad, previamente al inicio de nuestra actividad como organización, nuestra misión y visión en términos lo más concretos posible. La comunidad podrá así primero evaluar si nuestra misión y visión es compatible con los objetivos de esa sociedad, y podrá luego evaluar si la estamos cumpliendo efectivamente a través de una información transparente de nuestras acciones y sus resultados sobre el valor y el capital propio y ajeno. Esa misión deberá incluir reglas definidas para el trade off entre las vicisitudes que puedan sufrir el valor y el capital económico propio y ajeno, como consecuencia de nuestras acciones. Solo así la evaluación social tendrá sentido. Solo así se podrá saber si nuestra misión es compatible con la de la sociedad en la que nos desarrollamos y si nuestras acciones son compatibles con la misión definida por la propia organización.

Sin embargo, a pesar de que ya resulta muy complejo, entendemos que los problemas y dificultades no terminan aquí. ¿Alcanzará 
solo con la dimensión económica? No solo de pan vive el hombre, aunque sea poderoso caballero Don Dinero. Hemos dicho previamente que existen otros valores humanos distintos y seguramente superiores a los económicos. ¿Qué sucede con ellos ante nuestras acciones?

\section{Nueva "Crisis". ¿Y si Nuestro Marco Tiene También en Cuenta los Valores Humanos no Económicos?}

Recordemos que la axiología nos enseña que hay otros valores humanos distintos y superiores a los económicos: éticos, estéticos, vitales, religiosos, etc. El mismo IIRR Conceptual Frameworkantes citado habla de valor sin explicitar en ningún momento si se limita o no a su dimensión económica.

En especial, el caso de los entes en los que su misión no es el lucro pone en crisis la evaluación de valores puramente económicos. ¿Es posible evaluar negativamente a una ONG que obtuvo pérdidas económicas cuya principal causa resultaron las donaciones de alimentos realizadas a sus conciudadanos hambrientos? ¿Es responsable socialmente una ONG que "gana" valor económico para sí, aun a costa de no dedicar todos sus recursos al objetivo de su constitución?

La microeconomía tradicional también "sufre" ante estos casos y tiene que cambiar la tradicional regla de maximizar beneficios privados por algunas alternativas como las de minimizar costos medios y/o marginales.

Sin embargo, en un contexto en que la sociedad considera que todas las empresas, aun las que tienen claramente un fin de lucro, son responsables socialmente, este problema se extiende a todas las organizaciones. Será necesario en este modelo aclarar y transparentar aún más la misión, visión y especialmente definir previamente una jerarquía de valores humanos a respetar, que incluya junto al tradicional resultado económico también a los valores no económicos.

Habrá que tener en cuenta que pueden existir muy diversas misiones ligadas a otros aspectos de valores humanos, pero que siempre habrá que tener en mira los efectos sobre el valor económico propio, ya que una organización que no posea medios para actuar simplemente se extinguirá y no podrá realizar ningún otro valor humano²2.

Todo se torna mucho más difícil, pero mucho más real, respecto de los modelos hedónicos que suponen un - economicus. Aquí la evaluación cualitativa es requerida necesariamente y muchas veces se impone a lo meramente cuantitativo. En este campo entran en crisis los intentos de mantener exclusivamente sistemas de información basados en la partida doble, más allá de su innegable importancia. Se hace realidad aquello de que "If people do not believe that mathematics is simple, it is only because they do not realize how complicated life is" [si la gente no cree que las matemáticas son simples, es solo porque no se dan cuenta de lo complicada que es la vida] (Von Neuman, 1947 como se citó en Alt, 1972, p. 694).

Deberemos analizar aquí todos los valores humanos, utilizando, por ejemplo, las cuatro modalidades surgidas de la clasificación de Scheler expresada anteriormente. Al multiplicar los valores, surge la pregunta ¿también deberíamos multiplicar los "capitales" que cristalizan esos valores?

Se encuentran en este campo de los "capitales múltiples" propuestas aún más completas que la realizada en el IIRR Conceptual Framework.

En 2011, el International Integrated Reporting Council (IIRC) inició una iniciativa global de varios años para desarrollar un modelo ampliado de capital. A través de su proceso, identificaron seis tipos de capital que deberían incluirse en un informe integrado. Hemos incluido los seis en nuestro modelo (se identifican con un asterisco después de su nombre en nuestro modelo). Además de estos seis, hemos incluido cuatro más que nuestro análisis indica que son necesarios para una evaluación integral de la creación de valor. (Metaintegral, s.f., página inicial)

Vemos que en esta opción más completa, a la lista original descripta en el IIRR Conceptual Framework, se le agregan los capitales culturales, de salud, psicológico y espiritual. Resulta realmente sorprendente para cualquier economista 0 contador tradicional hablar de la existencia de un capital espiritual, pero creemos que la sociedad del siglo XXI nos obliga a cambiar nuestros enfoques. Si la contabilidad se ocupó siempre de valores y la categoría valor es un concepto social como señala el epígrafe inicial de nuestro trabajo ¿cómo no adecuar los valores a analizar contablemente ante un cambio de la sociedad en la que nos desarrollamos?

Entran ahora en juego en la evaluación, las escalas y los conflictos de valores. La evaluación multiatributo se complica aún más. ¿Será posible "reducir" un valor en otro u otros? ¿Son válidas algunas preguntas como las que siguen?

•¿Cuánto "vale" económicamente una o varias vidas humanas? ¿Valen todas iguales? cas?

- ¿Es posible compensar económicamente las fallas éti-

-¿Qué nivel de otros valores que se realicen puede, por ejemplo, compensar una falta a la verdad? 
La pandemia a la que nos enfrentamos en este 2020 nos trae ejemplos de estos problemas de ética aplicada todos los días. Una versión de la prensa europea, rescatada de un largo reportaje al presidente argentino, nos ilustra sobre el atractivo que posee la utilización de comparaciones cuantitativas, aun en situaciones realmente inmensurables, y de la necesidad de estudios más profundos en este campo, aunque más no sea para comunicar mejor sobre situaciones complejas a la comunidad.

En abril de 2020,

el presidente de Argentina, Alberto Fernández, ha rechazado el 'dilema' entre economía y salud ante la crisis del coronavirus por considerarlo 'falso'. 'Prefiero tener 10 por ciento más de pobres y no 100.000 muertos en la Argentina por coronavirus ... . De la muerte no se vuelve, pero de la economía se vuelve', ha remachado. 'Los que plantean el dilema entre la economía y la salud, están diciendo algo falso'. (Europapress, 2020, párr. 1-3)23

No es fácil decidir entre valor económico y posibilidad de afectación de vidas humanas, y menos sencillo aún es reflejar ese conflicto en los reportes contables de responsabilidad social. Más difícil aún es definir cuáles vidas humanas son más significativas. En esta pandemia, ¿deberemos privilegiar la vida de los seres humanos que fallecieron en la primera ola del COVID-19, los que son afectados en la segunda ola, los que verán destruido su equilibrio mental por el encierro al que obliga la cuarentena, los que vean destruido su futuro económico o los que seguramente fallezcan por la atención interrumpida de afecciones crónicas previas? La infinidad de casos concretos que nos muestran los Ilamados trolley problems ${ }^{24}$ en ética aplicada nos permite entrever la complejidad de la temática.

En el fondo, la discusión entre visión "fuerte" y la visión "débil" de la sustentabilidad es un caso específico de estos problemas generales. ¿Es posible una sustitución casi perfecta de todas las clases de recursos naturales de los que dispone una sociedad por otros de otras clases y similares capacidades de generación de bienes y servicios, suponiendo así que ningún recurso puede ser irreductible en las demás categorías, 0 algunos recursos naturales son imprescindibles determinando su jerarquía e irreductibilidad en otros recursos para garantizar el bienestar de las generaciones futuras?

Una respuesta ante esta complejidad es simplemente negar la posibilidad de integrar los valores económicos con el resto de los valores humanos, como los ambientales y los religiosos, por resultar ínsitamente contrapuestos, por lo que todos estos intentos de armonización serán infructuosos:

Desarrollo y sostenibilidad obedecen a lógicas contrapuestas. El desarrollo ... . existente es lineal, creciente, explota la naturaleza y privilegia la acumulación privada. Es la economía política de corte capitalista. La. . . sostenibilidad. . . proviene de las ciencias de la vida y de la ecología, cuya lógica es circular e incluyente. .. Como se deduce, son lógicas antagónicas: una privilegia al individuo, la otra al colectivo; una promueve la competición, la otra la cooperación; una la evolución del más apto, la otra la evolución de todos interconectados. (Boff, 2013, párr. 5$)^{25}$

Otra posición es, reconociendo las dificultades de esta labor, redoblar nuestros esfuerzos y seguir trabajando para buscar modelos y marcos que nos permitan avanzar en el camino de esa ansiada integración, sin limitarla a un burdo reduccionismo económico ${ }^{26}$. Como ejemplo, entre muchos otros, podemos señalar el Integrated Social Accounting (ISA) Model basado en los Objetivos del Desarrollo Sostenible (ODS). Se propone allí un Modelo Integrado de Contabilidad Social que abarca diversos aspectos internos y externos del ente, que analiza en particular el impacto sobre la sociedad de las acciones de la organización emisora del informe en relación con los ODS propuestos por las Naciones Unidas, sin desdeñar los efectos sobre el valor económico creado para el propio ente.

En palabras de la propia autora del modelo:

A new integrated social accounting (ISA) model that expands its focus to align with societal impact is proposed. Whereas the NISA model motivates and monitors organization performance toward achieving an organization's mission, ISA focuses on both inward-facing and outward-facing organizational and societal goals using the lens of the sustainable development goals (SDGs). This ISA model consists of four interconnected dimensions: 1) resources/capitals, 2) value creation/destruction, 3) internal systems and processes, and 4) organizational learning, growth, and innovation. . Through these four dimensions, organizations link performance management and impact measurement, addressing efficiency and effectiveness, functional and strategic accountability, and feedback and adjustment. The SDGs provide the common lens that allows for organizations to take collective impact [Se propone un nuevo modelo de contabilidad social integrada (CSI) que expande su enfoque para alinearse con el impacto social. Mientras que el modelo NISA

${ }^{23}$ Es difícil aceptar que no exista dilema alguno. Obsérvese que al cuantificar las opciones, implícitamente parecería aceptar que existiría algún nivel más bajo de mortalidad aceptable a cambio de evitar un aumento del $10 \%$ de la pobreza. El problema de la inmensurabilidad vuelve. ¿Serán $90.000,50.000$ o sólo 1 persona respecto de la que podamos evitar su muerte?

${ }^{24} \mathrm{Cfr}$. entre muchos otros Bauman et al. (2014).

${ }^{25}$ En el mismo sentido "nadie puede servir a dos señores; porque aborrecerá a uno y amará al otro; 0 bien se entregará a uno y despreciará al otro. No podéis servir a Dios y al Dinero" (Mateo 6:24). Aunque otros sostienen la posible compatibilidad en el marco del mismo evangelio sobre la base del "dad a César lo que es del Céser, y dad a Dios lo que es de Dios" (Mateo 22:21).

y dad a Dios lo que es de Dios" (Mateo 22:21). En septiembre de 2020 se produjo un hito que podrá resultar fundamental en el proceso de integración de los reportes sobre sostenibilidad al sistema de los reportes contables en general. La Fundación IFRS publicó el Documento de Consulta de Información sobre Sostenibilidad iniciando un proceso para el posible dictado de normas sobre el tema por un Consejo integrado al sistema del IFRS. Al momento de finalizar la redacción de este trabajo se encuentra en consulta una Propuesta de modificaciones dirigidas a la Constitución de la Fundación IFRS para la creación de un Consejo de Normas Internacionales de Sostenibilidad para emitir Normas NIIF de Sostenibilidad. Este hito sirvió de base para la fusión entre ese Consejo y el Integrated Reporting Council que determinó la integración de la Value Reporting Foundation. 
motiva y monitorea el desempeño de la organización hacia el logro de la misión de una organización, CSI se enfoca tanto en objetivos organizativos y sociales orientados hacia adentro como hacia afuera, usando la lente de los objetivos de desarrollo sostenible (ODS). Este modelo CSI consta de cuatro dimensiones interconectadas: 1) recursos / capitales, 2) creación / destrucción de valor, 3) sistemas y procesos internos, y 4) aprendizaje organizacional, crecimiento e innovación. . . A través de estas cuatro dimensiones, las organizaciones vinculan la gestión del desempeño y medición de impacto, abordando la eficiencia y la efectividad, la responsabilidad funcional y estratégica, y la retroalimentación y el ajuste. Los ODS proporcionan la lente común que permite a las organizaciones evaluar su impacto colectivo]. (Mook, 2019, p. 82)

Los reportes de las organizaciones en este marco no deberán limitarse a agregar a la información contable tradicional los efectos económicos directos e indirectos sobre terceros y las generaciones futuras, sino que deberán incluir información significativa sobre los efectos que generan las acciones de la organización sobre el resto de los valores humanos, relacionando su informe con la jerarquía de valores asumidos por la propia organización al momento de su constitución. Una interesante forma de organización de estos informes resultaría clasificar la información en relación con las distintas categorías de valores afectados, expuestos en la jerarquía que la propia organización les reconoce.

A pesar de recordar siempre que "la Contabilidad [tradicional] trata exclusivamente de cuestiones económicas. . . no trata cuestiones de fiIosofía, religión, derecho, medicina, física o ninguna otra disciplina" (Mc Neal, 1939 como se citó en Di Russo y Hauque, 2002, p. 16), creemos fervientemente que este tipo de desafíos nos obliga a reanalizar el contenido de la contabilidad, trabajando siempre hombro a hombro con el resto de las disciplinas sociales.

Recordemos que el consejo de un genial epistemólogo nos guía también en este sentido:

No aísle la economía: trátela como un subsistema de la sociedad, por lo tanto como fuertemente acoplada con el medio ambiente natural, la organización política y la cultura. . . Fortalezca los vínculos entre la ciencia económica y sus vecinas. . . porque cada ciencia social estudia únicamente algunos aspectos de una única totalidad, a saber, la sociedad, y todos esos aspectos están interrelacionados y, por lo tanto, son interdependientes. (Bunge, 1999, p.174-175)

Aún dentro de este permanente conflicto de jerarquía e integración de valores, la sociedad podrá juzgar siempre que previamente la organización haya aclarado y transparentado:

\section{La elección de misión, visión y valores que la rijan.}

- Su efectivo cumplimiento en la realidad analizando sus acciones y resultados obtenidos.
Para traer un poco más de confusión a esta situación es necesario tener claro que en realidad muy poco está hoy realmente claro en el campo del estudio de la ética de los valores humanos.

Volpi lo ha expresado sin adornos al decir que el panorama de las teorías éticas contemporáneas es más bien un espectáculo babélico. Y agrega que la confusión es lo que reina soberanamente, y se puede ver desde el neoaristotelismo de Gadamer o la ética de la argumentación de Habermas y Otto Appel hasta la ética de la responsabilidad de Jonás. Sin olvidarse del utilitarismo del pensamiento angloamericano y el neocontractualismo, y concluye en que en una era dominada por el nihilismo 'las éticas permanecen en el plano de la homilética'. . . ¿Se han acabado entonces las esperanzas de contar con una ética que sirva de núcleo común a los distintos enfoques del pensamiento occidental contemporáneo sobre lo que ella misma significa y reclama? Quizás debamos aspirar no a una ética compartida, sino a compartir una actitud común en los planteamientos éticos. (Salort, 2018, pp. 11-12)

En este camino, al analizar la evaluación de la conducta de las organizaciones, es necesario recordar siempre que la aparente preocupación de los empresarios por el desarrollo de los valores humanos distintos a los económicos, muchas veces encubre la búsqueda de la maximización tradicional por métodos menos transparentes. Edward Bernays a finales de los años treinta ya sostenía que los hombres inteligentes debían darse cuenta de que la propaganda es el instrumento moderno para lograr una exitosa manipulación de la opinión pública. Entendía que el público tenía un carácter lento y reaccionario, y que quienes usan la psicología para modificar la opinión pública en el sentido que deseen están brindando un importante servicio público (0lasky, 1984, pp. 3-4). Resulta así difícil en los casos concretos diferenciar la verdadera intención de los comportamientos empresariales direccionados a la mejora de la sociedad en la que se desempeñan. Podrían ser originadas tanto en un verdadero compromiso de responsabilidad social como solo resultar parte de una estrategia empresarial para maximizar beneficios propios a través de una manipulación de la opinión pública para mejorar las condiciones de mercado de su empresa en particular.

Nos encontramos aquí ante el "psicópata" tradicional, solo que "disfrazado" de "altruista". Es un modelo de una persona que no hace lo que dice ni lo que verdaderamente piensa.

En las Consideraciones Preliminares de esta parte del trabajo, propusimos al lector que intente responderse a sí mismo la cuestión del contenido de su propio "reporte de responsabilidad social" a través de los distintos marcos que fuimos proponiendo. No son iguales las respuestas en el marco unidimensional del valor económico para sí que en el que considera el valor económico que se genera para otros y menos aún en el que intenta integrar todos los valores humanos. En todo caso, siempre será necesario tener definidos previamente como seres humanos en forma transparente nuestros valores y nuestra misión y visión para ser juzgados sobre esa base dentro del marco que consideremos aplicable. Dentro de una posmodernidad en la que el ser humano no reconoce generalizadamente algún ente supraindividual o supernatural 
que lo ayude a definir los valores que determinan, el pursuit of happiness como misión tradicional resulta tan terriblemente vago para cada caso concreto, que se asimila a un concepto vacío que cada ser humano puede Ilenar en forma totalmente distinta, según como se posicione dentro de esta confusa Babel de valores. Es decir que "a la filosofía, a la religión y a la ciencia, se les está acabando el tiempo. . . [ya que]. . . durante miles de años se ha debatido sobre el sentido de la vida" (Harari, 2018, p. 16).

\section{A MANERA DE CONCLUSIÓN Y DE PUNTO DE PARTIDA PARA CONTI- NUAR TRABAJANDO}

Creemos que para que el futuro cambie en un sentido positivo, necesitamos una contabilidad que mida o valore de forma distinta, incorporando aspectos que hasta ahora no considerábamos.

Si desea cambiar la realidad, una forma poderosa es cambiar lo que mide, cómo lo mide y por qué lo mide. Al medir y hacer más visible la realidad, podemos entrar en un diálogo más profundo con la realidad y así cultivar mayores formas de intimidad con ella. Para navegar con éxito en la complejidad del siglo XXI, necesitamos formas integradoras y no reductivas de medir el impacto y el intercambio de valor entre individuos y sistemas. (Esbjorn-Hargens, s.f., página inicial)

El trabajo busca además y especialmente Ilamar la atención sobre el inmenso problema que surge al intentar formular reportes sociales con el objetivo de determinar si una organización cumplió o no con su misión propuesta en el marco de sus propios valores, en los casos en que estos no hayan sido definidos en forma clara y concreta previamente. Consideramos así, en un mundo de valores babélicos, un requisito previo básico de cualquier proceso de evaluación una concreta definición de las reglas que se propone seguir la organización para efectivizar el trade-offentre las distintas jerarquías de valores involucrados en sus acciones. Sin ellas, nos encontraremos a ciegas para evaluar ex post su conducta.

Desde hace ya tiempo, la sociedad transita una etapa en la que el rol de las organizaciones en general y el de la empresa en particular ha ido avanzando hacia un modelo de responsabilidad social. Nos encontramos inmersos en una sociedad cada vez más activa, que demanda ejercer en forma plena su derecho a ser informada y busca rodearse de organizaciones comprometidas con el medio, que reconozcan los efectos que produce su accionar, incorporando a sus objetivos de maximización económica los de maximización del bienestar social, ambiental y espiritual.

Necesitamos así, tener la capacidad para hacer frente individualmente y como sociedad a situaciones novedosas e impensa- das, de manera eficiente y humana, y para ello tenemos que medir y valorar distinto y mejor.

The new nature of the problems faced in this third millennium (e.g., mad cow, genetic modified organisms, ... .), implies that very often when deciding on problems that may have long term consequences we are confronting issues 'where facts are uncertain, values in dispute, stakes high and decisions urgent' [la nueva naturaleza de los problemas que se enfrentan en este tercer milenio (por ejemplo, vaca loca, organismos genéticamente modificados. . .), implica que muy a menudo al decidir sobre problemas que pueden tener consecuencias a largo plazo, nos enfrentamos a problemas 'donde los hechos son inciertos, los valores están en discusión, los riesgos son altos y las decisiones urgentes']. (Munda, 2004, p. 663) ${ }^{27}$

El problema central será elegir entre distintas alternativas en el derrotero del cumplimiento de la misión humana, siempre que tengamos claro cuál es nuestra misión como individuos y como sociedad. La esencia del problema económico, supuesto como permanente, es la elección ante la escasez de recursos, para la satisfacción de todas las necesidades, individuales y colectivas del presente y del futuro. Elegir siempre entre dos o más cursos de acción alternativos, cada uno con pros y contras, seguramente no totalmente definidos al momento de decidir, es la esencia del accionar humano. $Y$ al elegir uno de esos caminos, renunciamos a todos los demás ${ }^{28}$. Nunca es sencillo elegir en estos contextos de hechos inciertos, valores en discusión, altos riesgos y decisiones urgentes, pero hay que hacerlo en función de la jerarquía de los valores humanos, aunque estos estén sujetos permanentemente a discusión. Más aún, en ese proceso nos veremos obligados a elegir un concepto de lo que consideramos "valor".

A consequence of these deep subjectivities is that in any normative exercise connected to a social decision problem, one has to choose an operational definition of 'value' in spite of the fact that social actors with different interests, cultural identities and goals have different definitions of 'value' [Una consecuencia de estas subjetividades profundas es que en cualquier ejercicio normativo relacionado con un problema de decisión social, uno tiene que elegir una definición operativa de 'valor' a pesar de que los actores sociales con diferentes intereses, identidades culturales y objetivos tienen diferentes definiciones de 'valor']. (ONeill, 1993, como se citó en Munda, 2004, p. 663) 
Cuantificar y monetizar serán siempre herramientas simplificadoras, y a la vez reduccionistas, a las que podremos echar mano, teniendo siempre en mira la totalidad de los valores humanos. Quizás alguna vez logremos abandonar las disyuntivas de hierro que nos plantea la escasez de recursos económicos para cada vez más destinatarios, con cada vez más necesidades. Será ese el momento en el que las posibilidades de la especie humana se ensancharán y nos permitirán crecer en dimensiones superiores en la escala de valores definidos por la axiología. Por ahora, los valores económicos resultan evidentemente inferiores en cualquier escala razonable, pero al mismo tiempo son la base indispensable de la pirámide que nos permite crecer y desarrollarnos en el campo de los demás valores humanos superiores.

The economic problem may be solved, or be at least within sight of solution, within a hundred years. This means that the economic problem is not ... the permanent problem of the human race ... If the economic problem is solved, mankind will be deprived of its traditional purpose. Will this be a benefit? If one believes at all in the real values of life, the prospect at least opens up the possibility of benefit . . it will be those peoples, who can keep alive, and cultivate into a fuller perfection, the art of life itself and do not sell themselves for the means of life, who will be able to enjoy the abundance when it comes. . . When the accumulation of wealth is no longer of high social importance, there will be great changes in the code of morals. We shall be able to rid ourselves of many of the pseudo-moral principles which have hag-ridden us for two hundred years, by which we have exalted some of the most distasteful of human qualities into the position of the highest virtues. We shall be able to afford to dare to assess the money-motive at its true value. The love of money as a possession -as distinguished from the love of money as a means to the enjoyments and realities of life- will be recognised for what it is, a somewhat disgusting morbidity, one of those semicriminal, semi-pathological propensities which one hands over with a shudder to the specialists in mental disease. . . I look forward, therefore, in days not so very remote, to the greatest change which has ever occurred in the material environment of life for human beings in the aggregate. [El problema económico puede resolverse, 0 al menos estar a la vista de la solución, dentro de cien años. Esto significa que el problema económico no es ... el problema permanente de la raza humana. . . Si se resuelve el problema económico, la humanidad se verá privada de su propósito tradicional. ¿Será esto un beneficio? Si uno cree en los valores reales de la vida, la perspectiva al menos abre la posibilidad del beneficio ... serán esos pueblos quienes puedan mantenerse vivos y cultivarse en una perfección más plena y no venderse ellos mismos para sobrevivir, que podrán disfrutar de la abundancia cuando llegue. . . Cuando la acumulación de riqueza ya no sea de gran importancia social, habrá grandes cambios en el código de la moral. Podremos deshacernos de muchos de los principios pseudomorales que nos han hostigado durante doscientos años, mediante los cuales hemos exaltado algunas

\begin{abstract}
de las cualidades humanas más desagradables como si fueran las más altas virtudes. Podremos permitirnos atrevernos a evaluar al dinero en su verdadero valor. El amor al dinero como posesión, a diferencia del amor al dinero como medio para el disfrute de la vida, será reconocido por lo que es, una patología un tanto repugnante, una de esas propensiones semicriminales, semipatológicas que se entrega con un estremecimiento a Ios especialistas en enfermedades mentales. . Espero, por 10 tanto, en días no tan remotos, el cambio más grande que haya ocurrido en el entorno material de la vida para los seres humanos en conjunto]. (Keynes, 1930, p. 4-7)
\end{abstract}

En la actualidad es fácil discernir que lamentablemente no será factible lograr este objetivo en 2030 como lo deseaba Keynes. Sin embargo, consideramos que no debemos dejar de perseguir sin pausa esta utópica y desafiante misión humana, a pesar de que, paradójicamente, en ese estadio futuro, nuestros antiguos y tradicionales reportes contables perderán su actual importancia.

\section{REFERENCIAS}

Alt, F. (1972). Archaelogy of computers: Reminiscences, 1945-1947. Communications of the ACM, 15(7), 693-694.

Bauman, C., McGraw, A., Bartels, D. y Warren, C. (2014). Revisiting external validity: Concerns about trolley problems and other sacrificial dilemmas in moral psychology. Social and Personality Psychology Compass, 8(9), 536554.

Boff, L. (2 de marzo de 2013). Desarrollo y sostenibilidad, en veredas opuestas. La Nación. https://www.lanacion. com.ar/comunidad/desarrollo-y-sostenibilidad-en-veredas-opuestas-nid1558824/?outputType=amp

Bunge, M. (1999). Las ciencias sociales en discusión: Una perspectiva filosófica (Trad. T. Aguilar Aks). Sudamericana.

Casares Ripol, J. (2011). Ética, Economía y Política. ESIC.

Di Fenizio, F. (1958). Economía Política (Trad. F. Estape, $2^{\mathrm{a}}$ ed.). Bosch.

Di Russo, L. y Hauque, S. (2002). Fundamentos Económicos de la Disciplina Contable. Librería Cívica.

Esbjorn-Hargens, S. (s.f.). [Página inicial]. Metaintegral. Recuperado el 3 de octubre de 2020 de https://www.metaintegral.com 
Esteban, S. y Sánchez, E. (13 de diciembre de 2003). Valor y Precio. El País. https://elpais.com/diario/2003/12/14/negocio/1071413247_850215.html

Europapress. (12 de abril de 2020). Alberto Fernández defiende las restricciones: "Prefiero tener 10\% más de pobres y no 100.000 muertos". https://nww. europapress.es/internacional/noticia-alberto-fernandez-defiende-restricciones-prefiero-tener-10-mas-pobres-no-100000-muertos-20200412152207. html

Friedman, M. (13 de septiembre de 1970). A Friedman doctrine - The Social Responsibility Of Business Is to Increase Its Profits. The New York Times. https://www.nytimes.com/1970/09/13/archives/a-friedman-doctrine-the-social-responsibility-of-business-is-to.html

García, I. (2005). Carácter epistemológico de la afirmación "el hombre es la medida de todas las cosas". Saga. Revista de Estudiantes de Filosofía, 6(12). https://revistas.unal.edu.co/index.php/saga/article/view/15006

García Morente, M. (1957). Lecciones preliminares de filosofía (6ª Edición). Losada.

Guzman, A. y Meyer, T. (2010). International soft law. Journal of Legal Analysis, 2(1), 171-225.

Harari, Y. (2018). 21 lecciones para el siglo XXI ( $2^{\mathrm{a}}$ ed.). Debate

Hauque, S. y Di Russo, L. (2013). Posibilidades y límites para una convergencia entre micro y macrocontabilidad. Capic Review, 11(2), 61-73.

Hauque, S., Di Russo, L., del Barco, J. y del Barco, M. (2016). Responsabilidad Social Empresarial: una mirada axiológica. Ediciones UNL.

Huxley, A. (2020). Un mundo feliz (Trad. R. Hernández). Debolsillo. (Obra original publicada en 1932).

International Accounting Standards Board. (2018). El Marco Conceptual para la Información Financiera. https://www2. deloitte.com/content/dam/Deloitte/cr/Documents/audit/ documentos/niif-2019/El\%20Marco\%20Conceptual\%20 para\%20la\%20Informaci\%C3\%B3n\%20Financiera.pdf

Jorgensen, E. (2005). Four philosophical models of the relation between theory and practice. Philosophy of Music Education Review, 13(1), 21-36.

Keynes, J. (1930). Economic Possibilities for our Grandchildren. Recuperado el 17 de julio de 2021 de http://www. econ.yale.edu/smith/econ116a/keynes1.pdf.
Koslowsky, P. (1996). Ethics of capitalism and critique of sociobiology: two essays with a comment by James M. Buchanan. Springer.

Ligteringen, E. y Zadek, S. (2005). The future of corporate responsibility codes, standards and frameworks. Global Reporting Initiative and AccountAbility. https://www.greenbiz.com/sites/default/files/ document/Custom016C45F63376.pdf

Lipsey, R. y Lancaster, K. (1957). The General Theory of Second Best. The Review of Economic Studies 24(1), 11-32.

Machado, A. (1951). Poesías completas. Losada.

Marimon, F., Alonso-Almeida, M., Rodríguez, M. y Klender Aimer Cortez, A. (2012). The worldwide diffusion of the global reporting initiative: what is the point? Journal of Cleaner Production, 33, 132-144.

Mattessich, R. (2002). Contabilidad y Métodos Analíticos Medición y Proyección del Ingreso y la Riqueza en la Macroeconomía y la Microeconomía. La Ley.

Mersch, I. (4 de febrero de 2019). The changing role of central banking. European Central Bank. https://www.ecb. europa.eu/press/key/date/2019/html/ecb.sp190204 fc6f950d31.en.html

Metaintegral. (s.f.). Descripción General-10 Tipos de Capital. Recuperado el 17 de junio de 2021 de https://www. metaintegral.com/

Mill, J. S. (1978). Principios de Economía Política (Trad. T. Ortiz.). Fondo de Cultura Económica. (Obra original publicada en 1848).

Mook, L. (2007). Social and environmental accounting: The expanded value added statement [Tesis de Doctorado no publicada]. University of Toronto.

Mook, L. (2019). The Sustainable Development Goals: A Tipping Point for Impact Measurement? Canadian journal of nonprofit and social economy research, 10(2).

Munda, G. (2004). Social multi-criteria evaluation: Methodological foundations and operational consequences. European journal of operational research, 158(3), 662-677.

Naciones Unidas, Comisión Europea, Organización para la Cooperación y el Desarrollo Económico, Fondo Monetario Internacional y Banco Mundial. (2008). Sistema de Cuentas Nacionales. https:// www.cepal.org/sites/default/files/document/files/sna2008_web.pdf 
Olasky, M. (1984). Retrospective: Bernays' doctrine of public opinion. Public Relations Review, 10(3), 3-12.

Pomeroy, L. (2013). To be or not to be: The Self, Continued: «No Man is an Island». Journal of Formal Axiology, 6, 93-98.

Real Academia Española. (s.f.). Ética. En Diccionario de la Lengua Española. Recuperado el 16 de junio de 2021, de https://dle.rae.es/ético?m=form

Real Academia Española. (s.f.). Evaluar. En Diccionario de la Lengua Española. Recuperado el 16 de junio de 2021, de https://dle.rae.es/evaluar?m=form

Real Academia Española. (s.f.). Responsabilidad. En Diccionario de la Lengua Española. Recuperado el 16 de junio de 2021, de https://dle.rae.es/responsabilidad?m=form

Rumoroso Rodríguez, J. (2013). Axiología y ética en Max Scheler. Logos. Revista de Filosofía, 41(122), 21-44.

Salort, D. (2018). Perspectivas contemporáneas en ética. Enfoques: revista de la Universidad Adventista del Plata, 30(2), 1-15.

Sikka, P. (2010). Smoke and mirrors: Corporate social responsibility and tax avoidance. Accounting forum, 34(3-4), 153-168. https://doi.org/10.1016/j.accfor.2010.05.002

Sombart, W. (1984). El apogeo del capitalismo. Fondo Cultura Económica.

Stiglitz, J. y Rosengard, J. (2016). La Economía del Sector Público (4⿳a ed.). Antoni Bosch.

Stolzmann, R. (1956). Introducción filosófica a la economía. El Ateneo.

Value Reporting Foundation. (2021). International $<\mathbb{R}>$ Framework. https://integratedreporting.org/wp-content/uploads/2021/01/InternationallntegratedReportingFramework.pdf

Wilde, 0. (1893). Lady Windermere's Fan. Recuperado el 14 de julio de 2021 de https://www.gutenberg.org/files/790/790-h/790-h.htm

Yamagishi, T., Li, Y., Takagishi, H., Matsumoto, Y. y Kiyonari, T. (2014). In search of Homo economicus. Psychological Science, 25(9), 1699-1711. 